\title{
Evaluation of different solvent extracts of sweet flag rhizome, Acorus calamus (L.) on pulse beetle, Callosobruchus maculatus (F.)
}

\author{
M. Saranya*, S.J. Nelson, M. Paramasivam and C.A. Mahalingam \\ Department of Agricultural Entomology, \\ Tamil Nadu Agricultural University, Coimbatore-641 003, Tamil Nadu, India. \\ Received: 05-01-2019 \\ Accepted: 09-05-2019
}

DOI: 10.18805/IJARe.A-5200

\begin{abstract}
Investigation was conducted to test the insecticidal activity of sweet flag rhizome (Acorus calamus L.) extracts on Callosobruchus maculatus (F.) on cow pea in storage during 2016-2017 at the Department of Agricultural Entomology, Agricultural College and Research Institute, Coimbatore. Sweet flag (SF) extracts obtained by different extraction methods (soxhlet and mechanical shaker extraction) using various solvents viz., hexane, ethyl acetate and ethanol exhibited varied levels of insecticidal action on Callosobruchus maculatus (F.). Pulse beetle on cow pea seeds, there was a positive correlation between the concentration of the sweet flag extracts and the insecticidal action. The $\mathrm{LC}_{50}$ value of hexane, ethyl acetate and ethanol extract of SF obtained in soxhlet extraction for C. maculatus was 0.042, 0.230 and 0.069 per cent at 48 hours, respectively. The $\mathrm{LC}_{50}$ value of hexane, ethyl acetate and ethanol extract of SF obtained in mechanical shaker extraction for C. maculatus was $0.009,0.275$ and 0.069 per cent at 48 hours, respectively. Hexane extract of SF obtained from both extraction methods (soxhlet and mechanical shaker) showed cent per cent mortality at 0.09 and 0.1 per cent on $5^{\text {th }}$ day after treatment (DAT). For ethyl acetate and ethanol extracts of SF obtained from both extraction methods (soxhlet and mechanical shaker), caused more than 80 per cent mortality was observed on $6^{\text {th }}$ DAT at 0.09 and 0.1 per cent on pulse beetle respectively. On 90 DAT, hexane extract of SF obtained from both extraction methods and of ethyl acetate extract of SF obtained from mechanical shaker extraction, there was no progeny development of $C$. maculatus at 0.05, 0.07, 0.09 and 0.1per cent concentrations. Cent per cent mortality and there is no progeny development $C$. maculatus in 0.09 and 0.1 per cent of hexane extract of SF (both extraction methods) and ethyl acetate extract of SF (mechanical shaker extraction) treated cowpea seeds upto 90 days when compared to untreated control.
\end{abstract}

Key words: $C$. maculatus, Solvent extract, Sweet flag rhizome.

\section{INTRODUCTION}

Post-harvest losses are often more significant than crop losses which occur in the field. As in field crops, a wide range of insect pests also attack stored products. In pulses, over 200 species of insects have been recorded in India. Among these, pulse beetle (Callosobruchus spp.) is a major cosmopolitan pest that causes deterioration to a variety of stored legume grains. Pulse beetle is very important pest of grain legumes both in storage and in the field. It is distributed throughout India. It attacks peas, pigeon pea, black gram, green gram, horse gram and cow pea etc. Larva which grows inside eat endosperm and then seed is totally damaged. Adults are non feeding. Seed germination is spoiled even during developing stages of beetle. Adults come out of the seed after pushing out a circular lid prepared by prepupal stage of larvae.

In India pulses are grown on an area of 22 million hectares producing 13 million tonnes. The productivity of the crops have remained static for the six decades. The estimated availability of pulses has gone down from
$70.1 \mathrm{~g} /$ day/person during 1951 to $31 \mathrm{~g} /$ day/person in 2008 whereas Indian Council of Medical Research Recommends $65 \mathrm{~g} /$ day/person (Ready et al., 2012). Callosobruchus spp. can cause damage of legume seeds up to cent per cent during storage (Gbaye and Holloway, 2011). Damage caused by bruchid during storage may count 5.00-10.00 and 20.0030.00 per cent in the temperate and tropical countries, respectively (Kiradoo and Srivastava, 2010).

The control of foodstuff pests is also very difficult due to recent legislations that restrict the use of synthetic insecticides. Concerns about the residual toxicity of synthetic insecticides applied to stored grains and health hazards to grain handlers have prompted research for alternatives for protection of stored grains. Therefore, there is a worldwide need to find alternative molecules to traditional insecticides, in order to meet the growing demand for healthy and safe food (Yildirim et al., 2001). Attention has been given to the possible use of bioactive natural products or plant derived compounds as promising alternatives to synthetic insecticides in controlling insect pests of stored products (Ohazurike et al., 2003; Umoetok and Gerard, 2003).

\footnotetext{
*Corresponding author's e-mail: suganpraveen9@gmail.com
} 


\section{MATERIALS AND METHODS}

Mass culturing of $\boldsymbol{C}$. maculatus: The Callosobruchus maculatus population prevalent in and around Tamil Nadu Agricultural University were collected and utilized for mass culturing. These beetles were reared on fresh cowpea seeds following the method developed by Credland and Wright (1989). About $200 \mathrm{~g}$ of cowpea seeds were placed in $600 \mathrm{ml}$ plastic jars, into which approximately 50 pairs of freshly emerged $C$. maculatus adults were introduced. The plastic jars were covered with muslin cloth and placed in dark to facilitate maximum oviposition. Rearing was maintained at a room temperature of $30 \pm 5^{\circ} \mathrm{C}$ and $70 \pm 5 \%$ Relative humidity throughout the experiment period. After 25 to 30 days, adults that emerged from the culture were utilized for maintenance of sub cultures following the same procedure as described above. Sub culturing of this beetle was done at weekly intervals so as to get continuous supply of insects for experiments.

\section{EXTRACTION}

By soxhlet apparatus: The powdered sweet flag rhizome of $100 \mathrm{~g}$ was sequentially extracted with $700 \mathrm{ml}$ of hexane (non polar), ethyl acetate (medium polar) and ethanol (high polar) solvent on soxhlet's extraction apparatus for 6,10 and $10 \mathrm{hr}$, respectively. The solvents were evaporated in a rotary vacuum evaporator at $40^{\circ} \mathrm{C}$. The obtained extracts were pale yellow to pale brown in colour, viscous liquid, having a pleasant woody and spicy odour.

By mechanical shaker: Thirty grams of sweet flag rhizome powder were sequentially soaked in $150 \mathrm{ml}$ of hexane, ethyl acetate and ethanol solvent for overnight (16 hr) separately. Shaking was done in a mechanical shaker at $250 \mathrm{rpm}$ for $1 \mathrm{hr}$ on next day and the solvents were filtered through using whatmann No 1 filter paper. The filtered solvents were evaporated in a rotary vacuum evaporator at $40^{\circ} \mathrm{C}$. The obtained extracts were pale yellow to dark brown in colour, viscous liquid, having a pleasant woody and spicy odour.

Effect of rhizome extract of sweet flag on pulse beetle: Twenty grams of cowpea seeds at 12 per cent moisture content were taken in a plastic jar. Hexane, ethyl acetate and ethanol extracts of sweet flag at different concentrations viz., $0.005,0.007,0.03,0.05,0.07,0.09$ and 0.1 per cent w/v were added to the grains and shaken thoroughly. Untreated seeds were maintained as control. Three replications were maintained for each treatment. Thirty (15 pairs) newly emerged adults were released into each plastic jar. Mortality was recorded at $24 \mathrm{hrs}$ interval for seven days. Population of pulse beetle were recorded at one month after inoculation.

Statistical analysis: The data were subject to statistical analysis. Square root and arcsine transformations were adopted for the data transformation of numbers and percentage, respectively (Abbott, 1925). Means in simple CRD analysis were separated by Least Significant Difference (LSD) test.

\section{RESULTS AND DISCUSSION}

Effect of hexane extract of sweet flag on $C$. maculatus Extraction by soxhlet apparatus: On $3^{\text {rd }}$ DAT, hexane extract of sweet flag was caused 95.56 and 93.33 per cent mortality at 0.1 and 0.09 per cent concentration, respectively (Table 2). On $4^{\text {th }}$ DAT, cent per cent mortality was recorded at 0.09 and 0.1 per cent concentrations. On $6^{\text {th }}$ DAT, more than 90.00 per cent mortality was recorded in all the sweet flag hexane extract treatments while the untreated check showed no mortality. On $7^{\text {th }}$ DAT, cent per cent mortality was observed in $0.03,0.05,0.07,0.09$ and 0.1 per cent, while 0.005 and 0.007 per cent caused 97.78 and 98.89 per cent Mortality, respectively. There was no progeny production of C. maculatus at $0.05,0.07,0.09$ and 0.1 per cent concentration upto 90 days (Table 5). The LC ${ }_{50}$ value of hexane extract of sweet flag was 0.042 per cent for green gram seeds at $48 \mathrm{hr}$ (Table 1) (Fig 1 and 3).

Extraction by mechanical shaker: On $3^{\text {rd }}$ DAT, hexane extract of sweet flag was caused $67.78,67.78$ and 85.56 per cent mortality at $0.07,0.09$ and 0.1 per cent concentration, respectively (Table 2). On $5^{\text {th }}$ DAT, cent per cent mortality was recorded in 0.09 and 0.1 per cent concentrations while $0.005,0.007,0.03,0.05,0.07$ and 0.09 per cent concentrations recorded 55.56, 60.00, 92.22, 92.22, 98.89 and 98.89 per cent mortality, respectively. On $7^{\text {th }}$ DAT, cent per cent mortality was observed at all the tested doses except 0.005 and 0.007 per cent concentration while the untreated check showed no mortality. All the treatments were found to be superior over the untreated control. There was no progeny production of $C$. maculatus at 0.05, 0.07, 0.09 and 0.1per cent concentration upto 90 days (Table 5). The $\mathrm{LC}_{50}$ value

Table 1: $\mathrm{LC}_{50}$ of solvent extracts of sweet flag on C. maculatus after $48 \mathrm{hr}$ of treatments.

\begin{tabular}{lccccccc}
\hline Extraction methods & Solvents & Substrates & $\chi^{2}$ Value & Regression equation & LC $_{\mathbf{5 0}}$ & \multicolumn{2}{c}{ Fiducial limits } \\
\cline { 5 - 8 } & & & & & Lower & Higher \\
\hline Soxhlet apparatus & Hexane & Green gram & 0.415 & $\mathrm{y}=2.593 \mathrm{x}+8.854$ & 0.069 & 0.051 & 0.094 \\
& Ethyl acetate & Green gram & 0.921 & $\mathrm{y}=0.735 \mathrm{x}+5.462$ & 0.230 & 0.071 & 0.740 \\
& Ethanol & Green gram & 0.439 & $\mathrm{y}=2.804 \mathrm{x}+9.015$ & 0.068 & 0.055 & 0.086 \\
Mechanical shaker & Hexane & Green gram & 0.415 & $\mathrm{y}=2.593 \mathrm{x}+8.854$ & 0.069 & 0.051 & 0.094 \\
& Ethyl acetate & Green gram & 0.921 & $\mathrm{y}=0.735 \mathrm{x}+5.462$ & 0.230 & 0.071 & 0.740 \\
& Ethanol & Green gram & 0.439 & $\mathrm{y}=2.804 \mathrm{x}+9.015$ & 0.068 & 0.055 & 0.086 \\
\hline
\end{tabular}

*All lines are significantly good fit at $\mathrm{P}<0.05$. 


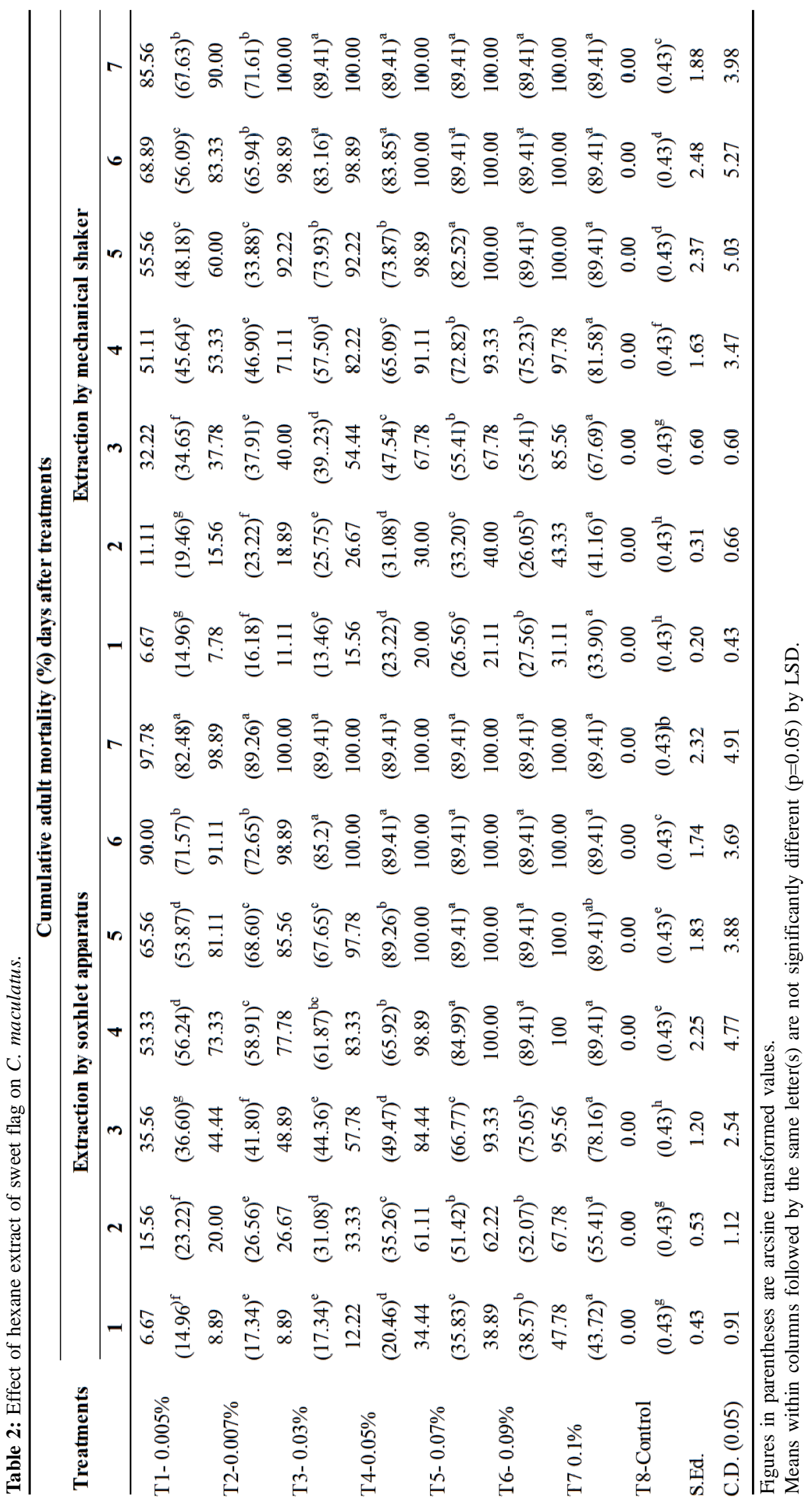


of hexane extract of sweet flag was 0.009 per cent for green gram seeds at $48 \mathrm{hr}$ (Table 1) (Fig 2 and 3).

\section{Effect of ethyl acetate extract of sweet flag on $C$.} maculatus

Extraction by soxhlet apparatus: On $6^{\text {th }}$ DAT, more than 70.00 per cent mortality was recorded in all the treatments except 0.005 per cent while the untreated check showed no mortality (Table 3 ). On $7^{\text {th }}$ DAT, 97.63 per cent mortality was observed at 0.1 per cent while $0.005,0.007,0.03,0.05$, 0.07 and 0.09 per cent caused $41.11,82.22,82.22,88.89$, 93.33 and 95.56 per cent mortality, respectively. On $7^{\text {th }}$ DAT, among different treatments, T7 $(0.1 \%)$ was significantly superior over all other treatments. At 0.09 and 0.1 per cent of ethyl acetate extract of sweet flag, 31.00 and 27.00 adults emerged, respectively upto 90 days (Table 5). The LC ${ }_{50}$ value of ethyl acetate extract of sweet flag was 0.230 per cent for green gram seeds at $48 \mathrm{hr}$ (Table 1) (Fig 1 and 3).

Extraction by mechanical shaker: The highest mortality of 58.89 per cent was recorded in 0.1 per cent of ethyl acetate extract of SF on $1^{\text {st }}$ DAT followed by 56.67, 54.4, 43.33, $33.33,27.78$ and 8.89 per cent mortality at $0.09,0.07,0.05$, $0.03,0.007$ and 0.005 per cent concentrations, respectively (Table 3 ). On $4^{\text {th }}$ DAT, cent per cent mortality was observed in both 0.09 and 0.1 per cent concentrations. On $6^{\text {th }}$ DAT, more than 80.00 per cent mortality was recorded in all the treatments except 0.005 per cent while the untreated check showed no mortality. On $7^{\text {th }}$ DAT, cent per cent mortality was observed at 0.05 and 0.07 per cent while $73.33,93.33$ and 95.56 was noticed at $0.005,0.007$ and 0.03 per cent respectively. Among different treatments, T6 (0.09\%) and T7 $(0.1 \%)$ were significantly superior over all other treatments. There was no progeny production of $C$. maculatus at $0.05,0.07,0.09$ and 0.1 per cent concentration upto 90 days (Table 5). The $\mathrm{LC}_{50}$ value of ethyl acetate extract of sweet flag was 0.275 per cent for green gram seeds at $48 \mathrm{hr}$ (Table 1) (Fig 2 and 3).

Effect of ethanol extract of sweet flag on $C$. maculatus Extraction by soxhlet apparatus: On $4^{\text {th }}$ DAT, ethanol extract of SF at 0.09 and 0.1 per cent concentrations was caused 37.78 and 43.33 per cent mortality, respectively (Table 4). On $7^{\text {th }}$ DAT, 97.25 per cent mortality was observed in 0.1 per cent while $0.005,0.007,0.03,0.05,0.07$ and 0.09 per cent registered $65.56,70.00,81.11,86.67,87.78$ and 95.56 per cent mortality, respectively. Among different treatments, T7 $(0.1 \%)$ was significantly superior over all other treatments. At 0.09 and 0.10 per cent of ethyl acetate extract of sweet flag, 64.00 and 51.00 adults emerged, respectively upto 90 days (Table 5). The LC ${ }_{50}$ value of ethanol extract of sweet flag was 0.069 per cent for green gram seeds at $48 \mathrm{hr}$ (Table 1) (Fig 1 and 3).

Extraction by mechanical shaker: On $4^{\text {th }}$ DAT, 0.09 and 0.1 per cent concentrations were showed 51.1 and 57.78 per cent mortality, respectively (Table 4$)$. After $6^{\text {th }}$ DAT, more than 60.00 per cent mortality was recorded in all treatments except 0.005 and 0.007 per cent concentrations. On $7^{\text {th }}$ DAT, cent per cent mortality was observed at 0.1 per cent while $0.005,0.007,0.03,0.05,0.07$ and 0.09 per cent registered $44.44,55.56,78.89,81.11,83.33$ and 87.78 per cent mortality respectively. On $7^{\text {th }}$ DAT, among different treatments, T7 $(0.1 \%)$ was significantly superior over all other treatments. At 0.09 and 0.10 per cent of ethanol extract of sweet flag, 57.00 and 44.00 adults emerged, respectively upto 90 days (Table 5). The $\mathrm{LC}_{50}$ value of ethanol extract of sweet flag was 0.069 per cent for green gram seeds at $48 \mathrm{hr}$ (Table 1) (Fig 2 and 3).

The solvent extracts of sweet flag rhizome exhibited insecticidal action on $S$. oryzae depending on their concentrations. Cent per cent mortality was observed on $7^{\text {th }}$ DAT in 0.1 per cent of hexane, ethyl acetate and ethanol extracts of sweet flag obtained from mechanical shaker and hexane extract got from soxhlet apparatus.

In case of hexane extract of sweet flag obtained from soxhlet extraction, cent per cent mortality was recorded at 0.09 and 0.1 per cent concentrations, on $4^{\text {th }}$ DAT. In hexane extract of SF, cent per cent mortality was noticed at 0.03 , 0.05 and 0.07 per cent concentrations on $7^{\text {th }}$ DAT. In ethyl acetate and ethanol extracts of SF, 97.63 and 97.25 per cent mortality were noticed at 0.10 per cent concentration on $7^{\text {th }}$ DAT respectively. In cow pea seeds, no progeny development was observed at $0.05,0.07,0.09$ and 0.10 per cent concentrations of hexane extracts of sweet flag up to 8 weeks.

In case of sweet flag extracts obtained in mechanical shaker, at 0.10 per cent concentration, cent per cent mortality was recorded on $5^{\text {th }}$ DAT in hexane and ethyl acetate extract while in ethanol, 66.67 per cent mortality was observed. On $7^{\text {th }}$ DAT, hexane extract and ethyl acetate extracts of SF showed cent per cent mortality at 0.03, 0.05, 0.07, 0.09 per cent concentrations. In ethanol extract, cent per cent mortality was noticed at 0.1 per cent concentration while it was 87.78 , $83.33,81.11,78.89,55.56$ and 44.44 at $0.09,0.07,0.05$, $0.03,0.007$ and 0.005 per cent concentrations on 7 DAT respectively. In cow pea seeds, no progeny development were observed at $0.05,0.07,0.09$ and 0.1 per cent concentrations of hexane and ethyl acetate extracts of sweet flag up to 8 weeks. This difference in the mortality rates of $C$. maculatus in the same host at same concentration may be due to the polarity of the solvents used in extraction.

The insecticidal action of the solvent extracts of sweet flag on $C$. maculatus observed in the present investigation can be corroborated with the findings of Shukla et al. (2016) who reported cent per cent mortality of $C$. chinensis at 0.05 and $0.1 \mu \mathrm{l} / \mathrm{ml}$ of sweet flag oil on 24 and $12 \mathrm{~h}$ exposure, respectively. At $0.15 \mu \mathrm{l} / \mathrm{ml}$, sweet flag oil caused cent per cent antifeedant activity, thereby, completely 


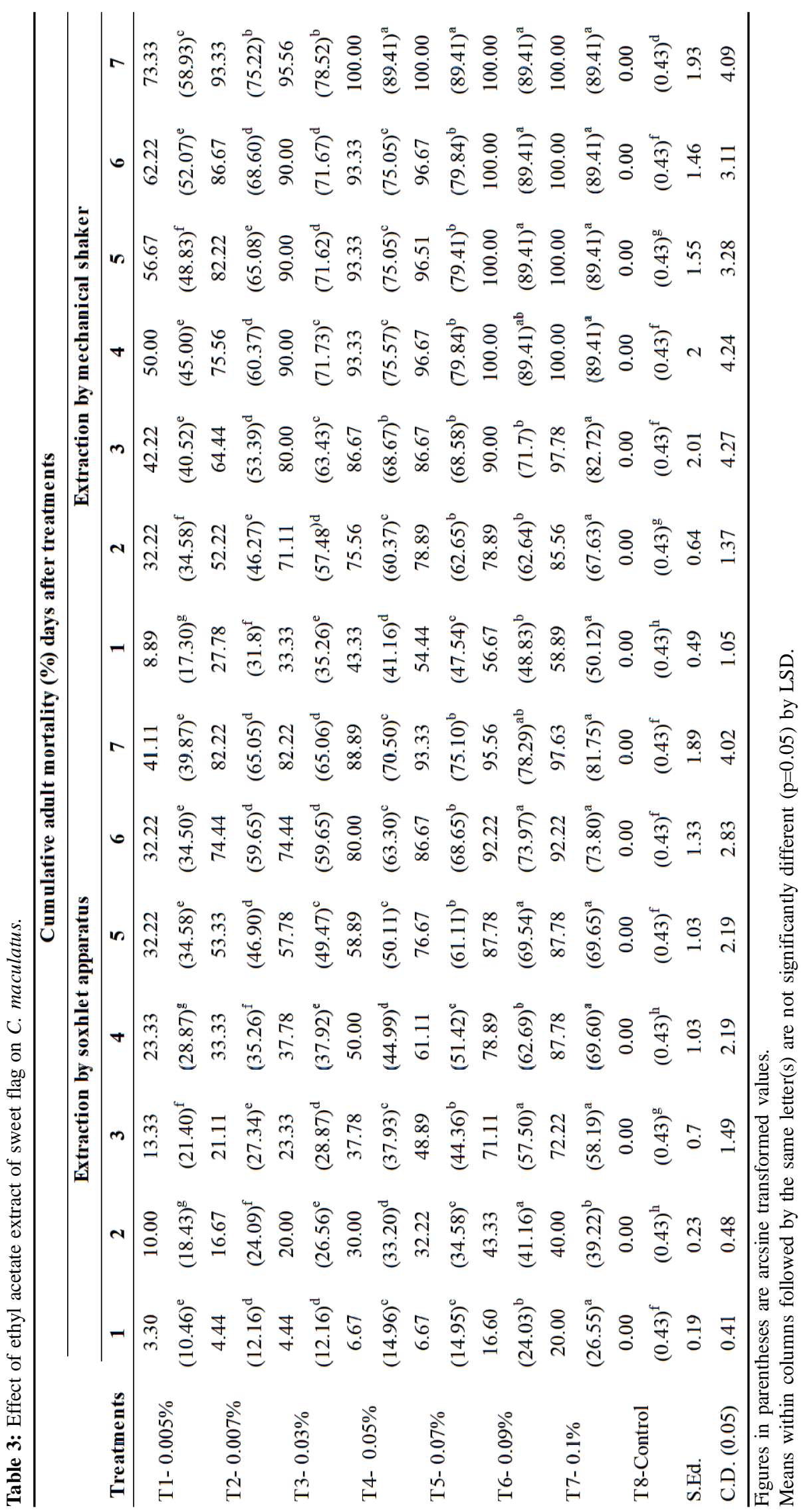




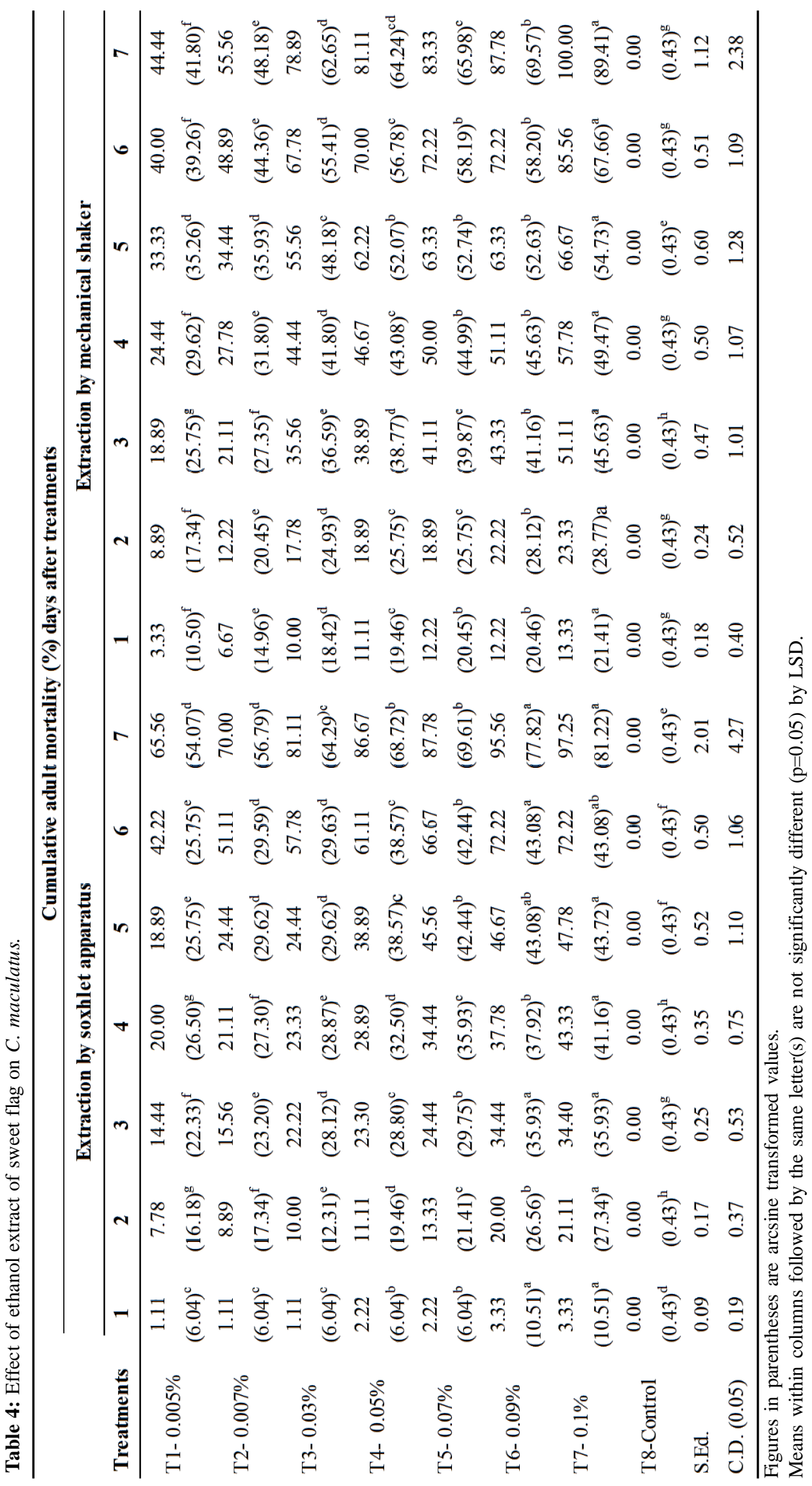


Volume 53 Issue 4 (August 2019)

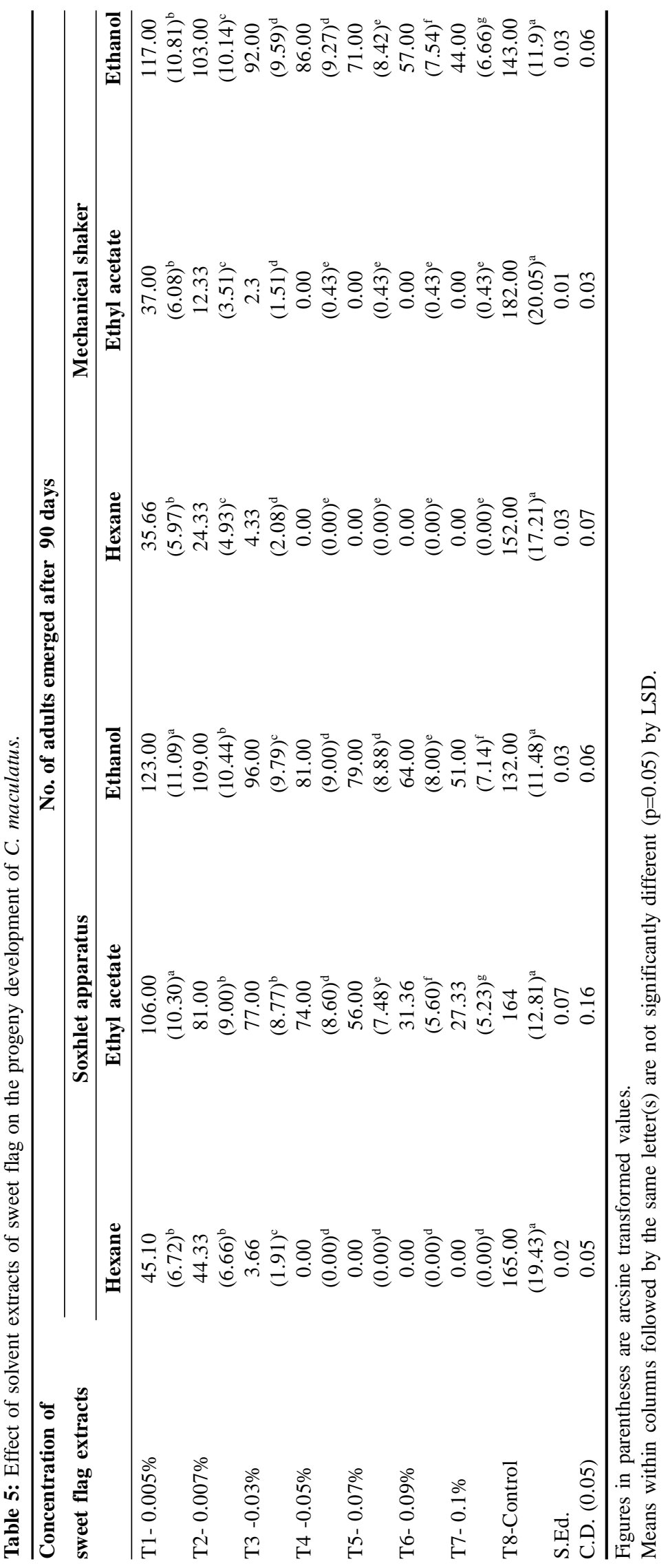




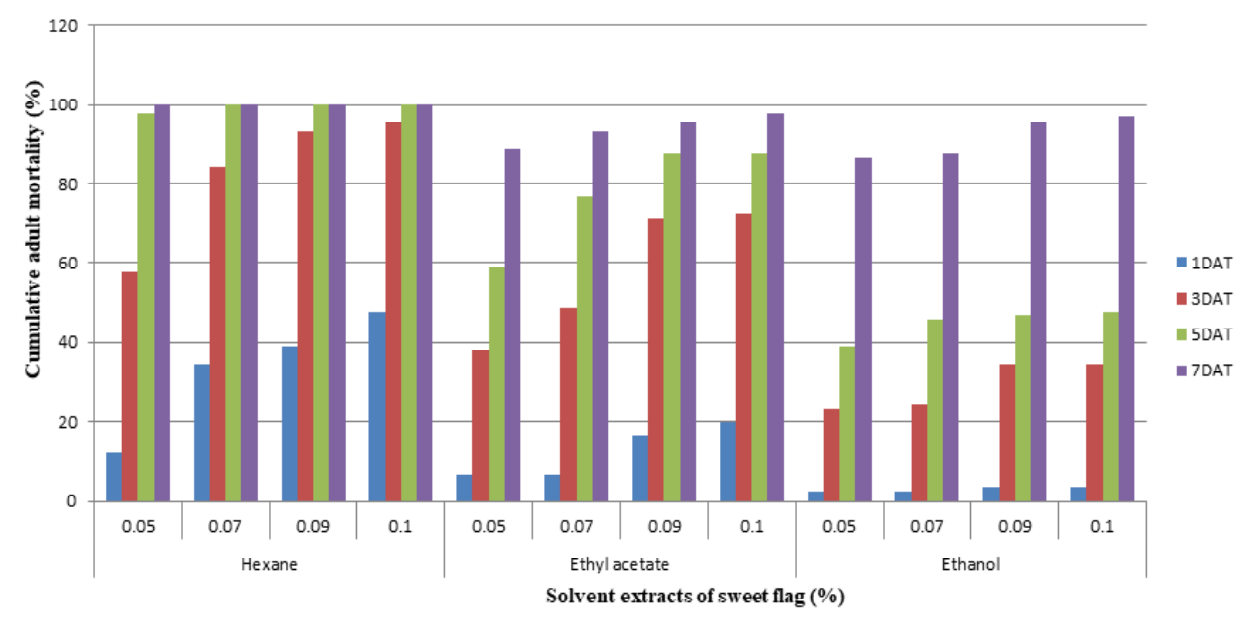

Fig 1: Mortality of C. maculatus due to extracts of sweet flag rhizomes by soxhlet apparatus.

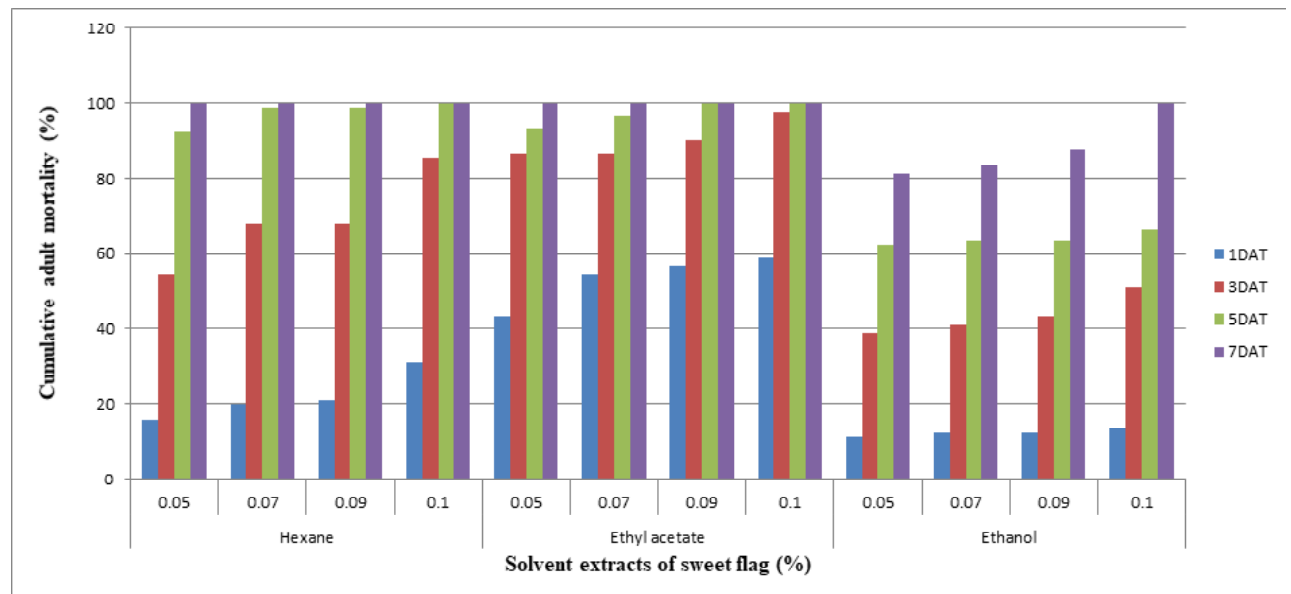

Fig 2: Mortality of $C$. maculatus due to extracts of sweet flag rhizomes by mechanical shaker.

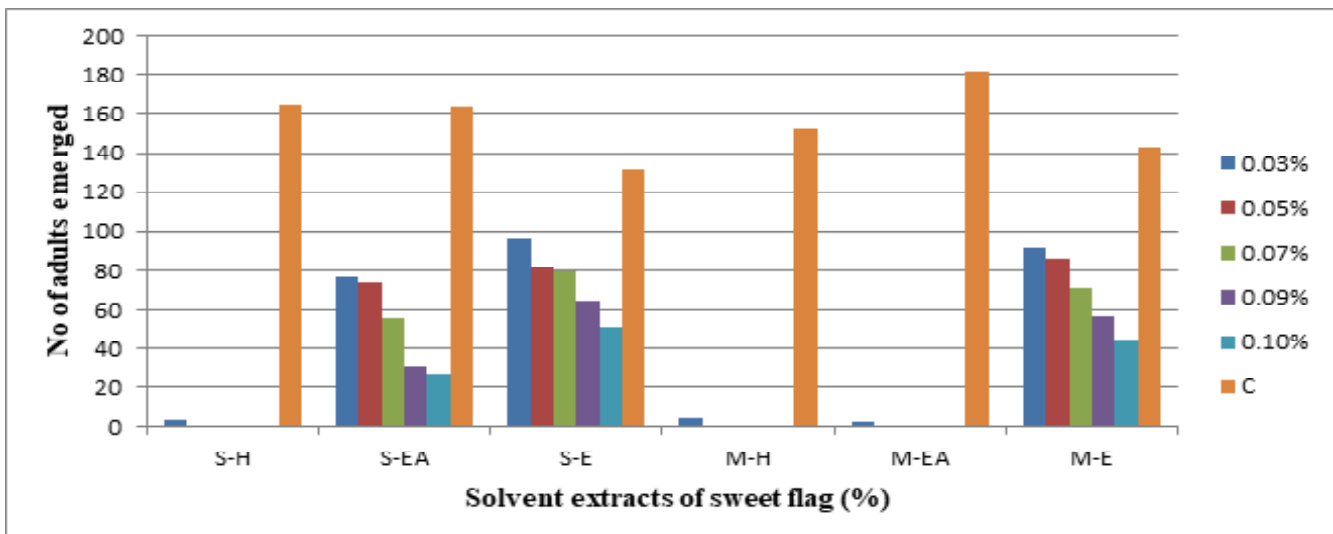

Fig 3: Effect of solvent extracts of sweet flag on the progeny development of C. maculatus.

S-H Hexane extract obtained from Soxhlet apparatus; S-E Ethanol extract obtained from Soxhlet apparatus M-H Hexane extract obtained from Mechanical shaker; M-E Ethanol extract obtained from Mechanical shaker SF- Sweet Flag; C- Control
S-EA Ethyl acetate extract obtained from Soxhlet apparatus

M-EA Ethyl acetate extract obtained from Mechanical shaker 
protecting the chickpea seeds from insect damage and weight loss. Kumar et al. (2016) also observed cent per cent mortality of C. chinensis at 2.5 and $1.25 \mathrm{ml} / \mathrm{kg}$ doses of sweet flag oil in $7^{\text {th }}$ DAT. The present findings also gain support from the reports given by Anbarasi (2014) who observed cent per cent mortality of $C$. maculatus within $24 \mathrm{hr}$, sweet flag EC formulation based on hexane, ethyl acetate, acetone, methanol and petroleum ether extracts at 1.0 per cent in green gram and toxicity persistence was upto 12 weeks. Similar results were observed by Dhivya (2016) who observed cent per cent mortality of $C$. maculatus, in green gram, black gram and bengal gram seeds at 1 per cent of sweet flag EC formulation based on hexane extract on 4 DAT. On 150 DAT, no seed damage was recorded in 0.4, 0.5, 0.6, 0.7, 0.8, 0.9 and 1.0 per cent of sweet flag EC formulation. Yadava (1971) reported that sweet flag rhizome powder in 2 and 4 per cent emulsions in water, with or without a small quantity of kerosene and in 4.00 per cent solution in absolute ethanol were found to have a rapid knockdown effect on the beetles and a prolonged residual effect on $C$. chinensis. Schmidt and Risha (1990) reported that $1 \mu \mathrm{l}$ of sweet flag oil was adequate to control newly-laid eggs of $C$. chinensis at $72 \mathrm{hr}$ exposure.

The present finding on inhibition of progeny development at $0.05,0.07,0.09$ and 0.10 per cent of hexane and ethyl acetate extracts of sweet flag up to 8 weeks can be corroborated with the findings of Rao et al. (1993) who reported that $A$. calamus had residual effects upto 90 days inhibiting oviposition and new progeny development. Sweet flag rhizome powder (SFRP) (1.00 per cent) mixed with mungbean inhibited emergence of adult C. maculatus (Pandey et al., 1977) and in stored bengal gram at a concentration of $0.10-0.50$ per cent was effective in arresting the development of the $C$. chinensis (Khan and Borle, 1985). Shivanna et al. (1994) reported that $0.50,1.50$ and $2.50 \mathrm{~g}$ $\mathrm{SFRP} / 50 \mathrm{~g}$ of seeds gave maximum protection against all three generations of $C$. chinensis. SFRP prevented egg laying of $C$. chinensis at one part per 100 parts of seed (w/w) and reduced the development at higher concentrations in other treatments $(1.50$ and 2.00 parts per 100 parts; w/w $)$ (Chiranjeevi and Sudhakar, 1996). The progeny of $C$. chinensis did not develop and the percentage infestation was 0-0.04, when $C$. chinensis were introduced 0-30 days after treatment with rhizome powder at 0.20 per cent, when the insects were introduced 45-120 days after the treatment, the infestation percentage was $0.26-0.93$ as compared with 19.59 in untreated grain (Khan, 1986). The A. calamus rhizome acted as a contact or stomach poison, or antifeedant and repellent on the newly emerged adults (Khan and Borle, 1985).

\section{REFERENCES}

Abbott, W.W. (1925). A method of computing the effectiveness of insecticide. J. Econ. Entomol. 18: 265-266.

Anbarasi, G. (2014). Effect of sweet flag Acorus calamus (L.) rhizome products on pulse beetle, Callosobruchus maculatus (F.) (Coleoptera: Bruchidae). M.Sc (Ag). Thesis. Tamil Nadu Agricultural University, Coimbatore, 101pp.

Chiranjeevi, C. and Sudhakar, T. R. (1996). Effect of indigenous plant materials on the fecundity, adult emergence and development of pulse beetle, Callosobruchus chinensis (L.) in blackgram. J. Res. APAU. 24(3-4): 57-61.

Credland, P. F. and Wright, A. W. (1989). Factors affecting female fecundity in the cowpea seed beetle, Callosobruchus maculatus Coleoptera: Bruchidae. J. Stored Prod. Res. 25(3): 125-136.

Dhivya.V. (2016). Studies on the toxicity of sweet flag, acorus calamus (1.) formulation on rice weevil, Sitophilus oryzae (L.) (Coleoptera : Curculionidae) and pulse beetle, Callosobruchus maculatus (F.) (Coleoptera: Bruchidae. M.Sc(Ag). Thesis. Tamil Nadu Agricultural University, Coimbatore, 170pp.

Gbaye, O. A. and Holloway, G. J. (2011). Varietal effects of cowpea, Vigna unguiculata on tolerance to malathion in Callosobruchus maculatus (Coleoptera: Bruchidae). J. Stored Prod. Res. 47: 365-371.

Khan, M. I. (1986). Efficacy of Acorus calamus L. rhizome powder against pulse beetle (Callosobruchus chinensis L.). PKV Res. J. 10(1): 72-74.

Khan, M. I. and Borle, M. N. (1985). Efficacy of some safer grain protectants against the pulse beetle, Callosobruchus chinensis L. infesting stored Bengal gram (Cicer arietinum L). PKV Res. J. 9(1): 53-55.

Kiradoo, M. M and Srivastava, M. A. (2010). Comparative study on the efficacy of two Lamiaceae plants on egg laying performance by the pulse beetle Callosobruchus chinensis Linn. (Coleoptera: Bruchidae). J. Biopestic. 3(3): 590-595.

Kumar, L., Verma, S. C., Sharma, P. L., Bhardwaj, B. D., Thakur. A. K. (2016). Evaluation of some essential oils against pulse beetle (Callosobruchus chinensis L.) in Pea Seeds. Adv Plants Agric Res. 5(4): 188-126.

Ohazurike, N.C., Onuh, M. O. and Emeribe, E.O. (2003). The use of seed extracts of the physic nut (Jatropha curcas L.) in the control of maize weevil (Sitophilus zeamaize M.) in stored maize grains (Zea mays L.). Global J. Agric. Sci. 2(2): 86-88.

Pandey, N. D., Singh, M., Tewari, G. C., Singh, M. (1977). Antifeeding, repellent and insecticidal properties of some indigenous plant materials against mustard sawfly, Athalia proxima Klug. Indian J. Entomol. 39(1): 60-64.

Rao, P. K., Aleem, M. A., Chitra K. C., Mani, A. (1993). Efficacy of some botanicals and ash against pulse beetle Callosobruchus chinensis (Linnaeus). Botanical Pesticides in Integrated Pest Management. 282-287.

Ready, A. A., Bantilan, M. C. S., Mohan, G. (2012). Enabling pulses revolution in India, ICRISAT, Policy brief No 26.

Schmidt, G. H. and Risha. E. M. (1990). Vapours of Acorus calamus oil are suitable to protect stored products against insects. Proc. Integrated Pest Management in Tropical and Subtropical Cropping Systems. 3: 977-997. 
Shivanna, S., Lingappa, S. and Patil, B. V. (1994). Effectiveness of selected plant materials as protectants against pulse beetle, Callosobruchus chinensis (Linn.) during storage of redgram. Karnataka J. Agric. Sci. 7(3): 285-290.

Shukla, R., Singh, P., Prakash, B., Dubey N. K. (2016). Assessment of essential oil of Acorus calamus L. and its major constituent $\beta$ asarone in postharvest management of Callosobruchus chinensis L., J. Essent. Oil. Bear. Pl. 19(3): 542-552.

Umoetok, S. B. A. and Gerard, M. B. (2003). Comparative efficacy of Acorus calamus powder and two synthetic insecticides for control of three major insect pests of stored cereal grains. Global J. Agric. Sci. 2(2): 94-97.

Yadava, R. L. (1971). Use of essential oil of Acorus calamus L. as an insecticide against the pulse beetle, Bruchus chinensis (L.). J. Appl. Entomol. 68(3): 89-294.

Yildirim, A., Mavi, A. and Kara. A. A. (2001). Determination of antioxidant and antimicrobial activities of Rumex crispus L. extracts. J. Agric. Food Chem. 49: 4083-4089. 